\title{
Fifty years of the Brazilian Marine Geology and Geophysics Program (PGGM)
}

\author{
Alex Cardoso Bastos ${ }^{1} \cdot$ Marcelo Sperle Dias ${ }^{2}$ \\ Published online: 16 May 2020 \\ (C) Springer-Verlag GmbH Germany, part of Springer Nature 2020
}

This special issue celebrates the 50th anniversary of the Brazilian Program of Marine Geology and Geophysics (PGGM). During the past 50 years, a number of national and international programmes were developed by Brazilian and foreign scientists in order to investigate and study the Brazilian continental margin and adjoining ocean basin. The first regional mapping of the Brazilian continental margin was carried out in the early 1970s (REMAC Project) and set the background for all the following marine geology and geophysics studies in Brazil. With more than $8000 \mathrm{~km}$ of coastline and a continental shelf territory of around 4.4 million $\mathrm{km}^{2}$, according to the last proposal presented at the United Nations Convention on the Law of the Seas (UNCLOS), knowledge and understanding of the Brazilian coastline and continental margin is of paramount challenge. The special issue, From the Coastal Zone to the Deep Sea, brings together 23 scientific articles ranging from nearshore sediment transport processes, records of sea-level and climate changes, coastal and marine stratigraphy, seabed mapping, benthic habitat mapping, and shelf and deep-sea sedimentation, with contributions coming from north to south Brazil. A new digital terrain model of the Brazilian continental margin is presented by Alberoni et al., showing the work developed by the Navy Hydrographic Center as a basis for the UNCLOS proposal. This new DTM compiles all the existing bathymetric data

Alex Cardoso Bastos

alex.bastos@ufes.br

1 Programa de Geologia e Geofísica Marinha, Dept Oceanografia, Universidade Federal do Espírito Santo, Av. Fernando Ferrari, 514 Goiabeiras, Vitória, ES 29060-900, Brazil

2 Programa de Geologia e Geofísica Marinha, Faculde de Oceanografia, Universidade Estadual do Rio de Janeiro, UERJ, Rio de Janeiro, RJ, Brazil along the Brazilian margin with Gebco Etopo and BNDO datasets. In terms of coastal processes, a discussion on tropical mesotidal barrier island-spit systems is presented by Silva and Vital, while Miranda et al. discuss the role played by cuspid spits on wave attenuation in a coastal lagoon (Lagoa dos Patos). Oliveira and Lessa present the dynamics of suspended macro-aggregates in a tropical estuary, and Ivanoff et al. apply geochronological methods to investigate recent sedimentation in a coastal lagoon. A review of fluid mud dynamics and its association with dredging in southern Brazil (Cassino Beach) is presented by Calliari et al. High resolution seismic is used to investigate an ebb-tidal delta at the entrance of Todos os Santos bay (Coni and Mello et al.). The role played by organic matter in the San Francisco delta clinoform is discussed by Escobar et al.

Continental shelf morphology and facies are presented mainly for the northeast Brazil. Morais et al., Moreira et al., and Silva and Gomes investigated mixed sedimentation shelves strongly related to semi-arid conditions and coastal erosion. Shelf geodiversity and its relation to benthic habitats is investigated along the Pernambuco shelf (NE Brazil, Lucatelli et al.), Espirito Santo shelf (E-SE Brazil, Oliveira et al.) and Rio de Janeiro shelf (SE Brazil, Ternes et al.). Halla et al. and Rangel et al. discuss the structural and ancient topography controlling morphology and sedimentation during the Late Quaternary along the eastern Brazilian shelf.

Deep-sea studies are presented in three articles: Deep pockmarks in the upper slope of the Santos Basin (Ramos et al.), Seismic stratigraphy of the Potiguar Basin and Touros High (Fonseca et al.), and the basement and the nature of the Santa Catarina Plateau (Jeck et al.).

Sea-level change records and climate variability are discussed in four articles, mainly for the southeast and south Brazil. Mid to Late Holocene hydrographic fluctuations in the South Brazilian Bight are proposed by Nagai et al. Neves presents an open discussion to sceptical researchers about how climate change can affect the coastal zone. Silva e Dias 
present a record of Pleistocene spodic horizon in the inner shelf of Rio de Janeiro state, while Dillenburg et al. discuss sedimentary records of MIS 3 in southern Brazil.

This volume provides an important reference for scientific studies from the Brazilian coastal zone to the deep sea. Improving our knowledge of the Brazilian continental margin has been one of the main objectives of the PGGM community over the last 50 years, and it will continue this way, with the future generations of Brazilian marine scientists. 